\title{
ENSAYOS
}

\section{El "Voucher" a la chilena. Reflexiones sobre elección escolar y financiamiento educacional}

\author{
The Chilean "Voucher". Reflections on school choice and educational funding
}

\author{
Catalina Canals ${ }^{a}$, Cristián Aguirre ${ }^{b}$, Christian Blanco ${ }^{c}$, \\ Felipe Fábregad, Camila Mena ${ }^{e}$, Nelson Paulus ${ }^{f}$ \\ a Instituto de Filosofía y Ciencias de la Complejidad (IFICC), \\ Centro de Investigación Avanzada en Educación, \\ Universidad de Chile. Telf.: (562) 29781255. \\ Correo electrónico: ccanals@ificc.cl \\ b Instituto de Filosofía y Ciencias de la Complejidad (IFICC). \\ Correo electrónico: cristianaguirre@gmail.com \\ ${ }^{\mathrm{c}}$ Facultad de Ciencias Sociales y Humanidades, \\ Universidad Autónoma de Chile. \\ Correo electrónico: chblancoj@gmail.com \\ ${ }^{\mathrm{d}}$ Instituto de Filosofía y Ciencias de la Complejidad (IFICC). \\ Correo electrónico: felipes.fabrega@gmail.com \\ e Instituto de Filosofía y Ciencias de la Complejidad (IFICC). \\ Correo electrónico: c.mena.carvacho@gmail.com \\ ${ }^{\mathrm{f}}$ Departamento de Historia, Facultad de Humanidades, \\ Universidad de Santiago de Chile (USACH). \\ Correo electrónico: nelson.paulus@usach.cl
}

\begin{abstract}
RESUMEN
El sistema educacional chileno es ampliamente identificado como Voucher. Este artículo revisa su implementación en Chile, analizando su conceptualización y diseño, a la luz de las teorías sobre Choice System (CS). El sistema chileno es un $C S$ originado por la pretensión de cambiar el modelo de desarrollo, más que por un diagnóstico común de problemas educativos. Es un modelo particular, que se distancia del Voucher de Friedman, al no existir un cupón entregado a las familias, pero más similar a la propuesta de Chubb y Moe, en la cual los colegios reciben un subsidio según su demanda. El modelo chileno no ha incorporado mecanismos importantes para empoderar a los padres. Las recientes reformas se alejan de las teorías de $C S$ al disminuir las libertades de la oferta, pero sin limitar la libertad de la demanda. Además, fomentarían un rol estatal más protagónico en otorgar información, lo que generaría mayor empoderamiento familiar.
\end{abstract}

Palabras claves: Choice System, subsidio dependiente de la demanda, Friedman, Chubb y Moe.

\section{ABSTRACT}

The Chilean educational system has been widely known as Voucher. This paper reviews its implementation at Chile, its conceptualization and design, in light of the theories of Choice System (CS). The system was implemented to change the development model rather than responding to a diagnosis of educational problems. It is a particular model, different from Friedman's Voucher, as there is no coupon given to families. It is more similar to the proposal of Chubb and Moe, where the schools receive a subsidy according to their demand. The Chilean 
model has not incorporated important mechanisms to empower parents. The recent reforms move away from the theories of CS by reducing the freedom of supply, but without limiting the freedom of demand. In addition, they would encourage a more proactive role of the state in granting information, which would generate higher family empowerment.

Key words: Choice System, Demand-Based Subsidy, Friedman, Chubb and Moe.

\section{INTRODUCCIÓN}

Aunque habitualmente se asocia al sistema escolar chileno con un sistema de "Voucher", el desarrollo, implementación y concreción de esta política en nuestro país exige un análisis desde los orígenes, a la luz de las teorías sobre Choice System (CS) y en sus distintas dimensiones.

Sin pretender proponer una aplicación "ortodoxa" de las teorías, se busca avanzar hacia una mayor rigurosidad conceptual y una mejor comprensión del modelo chileno. Particularmente, se hablará de voucher para referirse al cupón, es decir, al dispositivo material que, en la propuesta de Milton Friedman, se entrega a las familias para pagar la colegiatura; de Voucher para referirse al Choice System propuesto por Friedman, que incluye el uso de cupones; y de "Voucher" para referirse al CS chileno.

Luego de una descripción general de los CS, se desarrollarán tres etapas de análisis. Primero se compararán las orientaciones normativas que llevaron al establecimiento del "Voucher" en Chile con las pretensiones de las teorías en las que se inspira. Se argumentará que existe disonancia entre la fundamentación ideológica del modelo chileno respecto de las teorías de $C S$ (Tesis I).

En segundo lugar, se compararán las propuestas teóricas respecto al diseño de los $C S$ con la concreción chilena, previo a las reformas del segundo gobierno de Michelle Bachelet, planteando que (a) el diseño del modelo chileno difiere del modelo Friedmaniano y del de Chubb y Moe, asemejándose en mayor medida a este último (Tesis II), y, (b) el "Voucher" chileno carece de mecanismos de fomento al empoderamiento de las familias, ya sea mediante la entrega de cupón a las familias o la existencia de una oficina de información y orientación para la elección escolar (Tesis III). Ambas afirmaciones, implican plantear que el modelo chileno, más que un Voucher -como ampliamente se le ha identificado en la literatura- es un CS particular, en el cual el subsidio depende de la demanda (familias), pero es entregado a la oferta (escuelas) (Tesis IV).

Finalmente, se revisan las reformas educativas impulsadas desde el segundo gobierno de Michelle Bachelet y sus cambios al diseño del "Voucher" chileno. Estas reformas alejarán al modelo chileno de las propuestas de los teóricos de los CS en términos de liberalización de la oferta, sin limitar la libertad de la demanda, y fortaleciendo el rol del Estado en empoderar a la demanda (Tesis V).

Esta reflexión es relevante en tanto ofrece una mirada global a este CS particular, considerando aspectos económicos, sociales e históricos de la política pública. Hacia el futuro, el desarrollo del $C S$ chileno debe ser observado considerando los posibles cambios que introduzca el nuevo gobierno. 


\section{LAS PROPUESTAS DE CS: LA CREACIÓN DE UN MERCADO EDUCATIVO}

En EE.UU., en un contexto donde los estudiantes eran asignados a la escuela del barrio, donde los resultados en pruebas estandarizadas eran deficientes y había una creciente segregación racial del sistema escolar (Chubb y Moe, 1990) surgió la propuesta de los CS. El padre de estas propuestas es Milton Friedman (Levin 1968) con su Voucher (Friedman 1995). Un ejemplo de política de este tipo fue el GI Bill, que les permitía a los veteranos de la II Guerra Mundial usar un voucher para financiar su educación superior (Friedman 1955). Las propuestas de $C S$ en 1990 retoman importancia con la propuesta de Chubb y Moe (1990) (Levin 1992).

Los CS promoverían la descentralización, competencia y elección en el sistema escolar (Chubb y Moe, 1990), liberalizando la oferta y demanda educativa: las escuelas serán libres de ofrecer diversos servicios y los padres de elegir la escuela que gusten. El objetivo es garantizar libertad, diversidad y calidad (Friedman 1955; 1995; 2003; 2005; Friedman y Friedman 1980; 1982): la libertad sería entendida como la posibilidad de las familias de elegir; la diversidad, como la existencia de una oferta variada; y la calidad, como el efecto generado por la competencia entre escuelas para captar estudiantes.

Los $C S$ suelen utilizar subsidios estatales. Destacan aquellos con subsidio directo a la demanda ${ }^{1}$, que tiene en el Voucher de Friedman, su máxima expresión (Friedman y Friedman, 1980). En este, el financiamiento estatal es recibido por la familia en la forma de un cupón utilizable exclusivamente en la colegiatura (Larrañaga, 1994). La entrega del cupón sería un mecanismo de empoderamiento de la demanda, en tanto fomentaría la actitud de cliente que se traduce en: (a) la capacidad de elegir por calidad, (b) de exigir un buen servicio, y (c) de retirarse de un establecimiento insatisfactorio.

También hay $C S$ sin subsidio a la demanda, en el cual existe elección acotada a establecimientos públicos, que generalmente reciben subsidio a la oferta ${ }^{2}$ (Donoso y Schmal, 2002).

Un tercer tipo ha sido ampliamente asimilado al primero, pero presenta ciertas diferencias. Se denominará aquí "subsidio dependiente de la demanda" y ya fue propuesto por Chubb y Moe (1990), quienes señalaban que los establecimientos recibirían una subvención según la cantidad de estudiantes matriculados y, por tanto, competirían por captar alumnos. Este subsidio deriva del subsidio directo a la demanda, pero busca eficiencia al transferir recursos ${ }^{3}$. En esta propuesta el mecanismo de empoderamiento de la demanda consistiría en una política complementaria al subsidio: la existencia de Choice Offices, que mediarían la elección de los padres, entregándoles información y orientación en su toma de decisiones.

Un subsidio a la demanda puede implementarse como una reducción de los impuestos (Coons-Sugarman 1971), por lo que los sistemas de Individual tax credits and deductions (Ver EdChoice, 2018) entrarían en esta categoría.

2 El subsidio a la oferta potenciaría el desarrollo de la oferta educativa, según Parkin (2006).

Se ha sugerido que los subsidios a la oferta y a la demanda generan los mismos efectos: mayor cantidad del bien y menor precio (Mankiw 2004). La diferenciación de tipos de subsidios se justifica: (i) económicamente, porque la reducción de precio generada por un subsidio se puede desarrollar por distintos mecanismos (aumentando la oferta en el subsidio a la oferta y la demanda en el subsidio a la demanda). Con la asimilación del subsidio dependiente a la demanda con el directo a la demanda, no se ha evaluado si este aumenta la oferta y/o la demanda. (ii) sociológicamente, porque distintos tipos de subsidio implican (o no) la inclusión de mecanismos de empoderamiento de la demanda, cuyo efecto no ha sido estudiado en educación. 
Para el caso chileno, particular interés tienen los CS propuestos por Friedman, y Chubb y Moe. Aunque existen otras formas de concretar un CS (Coon y Sugarman, 1997) dan cuenta de las propuestas de otros teóricos y EdChoice (2018) resume algunos tipos de CS), es relevante comparar el sistema chileno con las propuestas de estos autores en tanto (i) usualmente el caso chileno es asimilado a un Voucher (por ejemplo, McEwan 2001, Sapelli y Torche 2002, Bellei 2008), (ii) pero cuenta con un subsidio dependiente de la demanda, similar al propuesto por Chubb y Moe ${ }^{4}$.

\section{DE LA INSTALACIÓN A LA CONSOLIDACIÓN DEL MODELO DE CS EN CHILE}

Las reformas de los 80 instalaron un modelo neoliberal con rol subsidiario del Estado (Valenzuela, Labarrera y Rodríguez, 2008). Previamente, el Estado tenía un rol docente, en el cual predominaban los colegios fiscales. El Ministerio de Educación (MINEDUC) designaba profesores, pagaba las remuneraciones de establecimientos públicos y fijaba programas para todo el sistema (Mizala y Romaguera, 1998).

Iniciando la dictadura (1973-1979) comenzó la instalación de autoridades castrenses en establecimientos educativos (Cruz, 2006) y la redefinición del currículo nacional para promover los "valores morales y espirituales propios de nuestra tradición chilena y cristiana" (Junta Militar 1974).

La Constitución de 1980 sentaría las bases del mercado educativo, consagrando la libertad de enseñanza como (a) el derecho a abrir y mantener escuelas y (b) el derecho de los padres a escoger el establecimiento de sus hijos. Con la Ley Orgánica Constitucional de Enseñanza (LOCE) de 1989 los cambios se consolidan, destacando: (1) la municipalización de establecimientos públicos (Cornejo, 2006); (2) la instalación de un sistema de subsidios estatales para establecimientos privados subvencionados y municipales según asistencia; y (3) la implementación de una prueba estandarizada nacional (Sistema de Medición de Calidad de la Educación, SIMCE). El sistema actual distingue tres tipos de establecimientos: municipales, particulares subvencionados y particulares pagados, que no reciben subvención.

Teóricamente, el nuevo modelo debía potenciar la libertad de elección de las familias para que los establecimientos compitieran por captar estudiantes, mejorando su calidad. Aunque la mayoría de la literatura reconoce estas reformas como un modelo Voucher, los padres nunca reciben un cupón (voucher) para cancelar la educación como lo propuso Friedman (1980; 1982; 2005).

A diferencia de donde surgieron las teorías del CS, la instalación del "Voucher" chileno se realizó con preexistencia de elección educativa (Donoso, 2006; Donoso y Schmal, 2002), sin asignación al colegio del barrio. Mientras en las teorías se buscaba el desarrollo del mercado educativo, para lograr mayor libertad, diversidad, calidad y no segregación; en Chile, la Junta Militar identificaba como problemáticas la repitencia, deserción, centralización y estatización excesiva (Espinoza y González, 1993). La Junta de Gobierno señalaba que la educación debía orientarse a trasmitir valores patrios, favorecer la libertad de enseñanza, asegurar la educación obligatoria y crear colegios públicos solo cuando la

Al no existir en el sistema chileno subsidio a la oferta o variaciones tributarias en función de la educación escolar, no parece necesario compararlo con dichas formulaciones de CS. 
iniciativa particular fuese insuficiente (Espinoza y González, 1993). Esto evidencia que el "Voucher" chileno fue producto de la voluntad ideológica de modificar el modelo de desarrollo del país (Donoso, 2006) imponiendo la subsidiariedad y un mercado educativo.

Desde 1990 se realizaron modificaciones al sistema que no alteraron los fundamentos del mismo, destacando (1) el financiamiento compartido o copago, que desde 1993 permite a colegios que reciben fondos públicos cobrar a las familias (Elacqua, Montt y Santos 2012), incluso en la enseñanza media municipal5; (2) la modificación en 1995 al estatuto docente para facilitar la movilidad de la planta docente y vincular remuneraciones con desempeño (MINEDUC 1997; Cox 1997); (3) el reemplazo de la LOCE por la Ley General de Educación (LGE) (MINEDUC 2009), que incluye la prohibición de la selección hasta sexto básico para escuelas con subvención (OPECH 2009); (4) la entrada en vigencia de la Ley de Subvención Escolar Preferencial (SEP) en 2009 (MINEDUC 2012b), que entrega una subvención adicional para estudiantes más vulnerables (Acevedo y Valenzuela 2011; Elacqua y Santos 2013). El sistema instalado en los 80, y modificado en los 90 y 2000 es lo que define el sistema escolar que actualmente opera. El segundo gobierno de Michelle Bachelet (2014-2018) aprobó reformas al sistema escolar, que modificarán el régimen vigente.

\section{EL DISEÑO DEL CS CHILENO ACTUAL}

A fin de caracterizar el sistema chileno, previo a la implementación de las reformas del segundo gobierno de Michelle Bachelet (2014-2018), este fue contrastado con las propuestas de Friedman, y Chubb y Moe (Tabla 1), se utilizaron las dimensiones de Gallego y Sapelli (2007) para definir un Voucher (financiamiento, regulación e información), y se añadieron dos dimensiones: modalidad de entrega del cupón y mecanismo de elección y postulación. Analizar el financiamiento y la regulación permite comprender las restricciones e incentivos que tiene la oferta escolar en el sistema. Analizar las dimensiones de regulación, información y el mecanismo de elección y postulación permite identificar el marco en que la demanda (las familias) eligen colegio. Finalmente, describir la modalidad de entrega del cupón permitirá diferenciar al sistema Voucher, de otros $C S$, además de profundizar en el impacto que dicha modalidad puede tener en oferta y demanda educativa. En suma, el conjunto de las cinco dimensiones permite caracterizar el escenario en el cual los agentes del sistema toman sus decisiones.

Los establecimientos municipales puedan implementar el copago en enseñanza Media con la aprobación de los apoderados, pero una minoría lo hace (Elacqua, Montt y Santos, 2012). 
Tabla 16: Comparación CS Chile, Chubb y Moe

\begin{tabular}{|c|c|c|c|c|}
\hline DIMENSIÓN & SUBDIMENSIÓN & FRIEDMAN & CHILE & CHUBB Y MOE \\
\hline \multirow{3}{*}{ Financiamiento } & $\begin{array}{l}\text { Gastos que cubre el } \\
\text { Estado }\end{array}$ & Colegiatura. & $\begin{array}{l}\text { Colegiatura, } \\
\text { alimentación. }\end{array}$ & $\begin{array}{l}\text { Colegiatura, } \\
\text { transporte. }\end{array}$ \\
\hline & $\begin{array}{l}\text { Posibilidad de } \\
\text { suplementar la } \\
\text { subvención }\end{array}$ & Suplementable. & $\begin{array}{l}\text { Suplementable, } \\
\text { determinado por } \\
\text { oferta. }\end{array}$ & $\begin{array}{l}\text { Suplementable, } \\
\text { determinado por } \\
\text { demanda. }\end{array}$ \\
\hline & $\begin{array}{l}\text { Heterogeneidad o } \\
\text { uniformidad de la } \\
\text { subvención }\end{array}$ & Uniformidad. & Heterogeneidad. & Heterogeneidad. \\
\hline \multirow{5}{*}{ Regulación } & $\begin{array}{l}\text { Requisitos a los } \\
\text { establecimientos } \\
\text { para incorporarse al } \\
\text { sistema }\end{array}$ & Ilimitado. & $\begin{array}{l}\text { Formalmente } \\
\text { limitado. }\end{array}$ & Ilimitado. \\
\hline & $\begin{array}{l}\text { Establecimientos } \\
\text { elegibles por las } \\
\text { familias }\end{array}$ & $\begin{array}{l}\text { Ilimitados } \\
\text { geográficamente. }\end{array}$ & $\begin{array}{l}\text { Ilimitados } \\
\text { geográficamente. }\end{array}$ & $\begin{array}{l}\text { Ilimitados } \\
\text { geográficamente. }\end{array}$ \\
\hline & $\begin{array}{l}\text { Posibilidad de } \\
\text { Selección escolar }\end{array}$ & No restringido. & $\begin{array}{l}\text { Formalmente } \\
\text { semi-restringido. }\end{array}$ & No restringido. \\
\hline & $\begin{array}{l}\text { Contenido } \\
\text { curricular }\end{array}$ & $\begin{array}{l}\text { Estándares } \\
\text { mínimos. }\end{array}$ & $\begin{array}{l}\text { Currículo } \\
\text { Nacional. }\end{array}$ & $\begin{array}{l}\text { Estándares } \\
\text { mínimos. }\end{array}$ \\
\hline & Personal & $\begin{array}{l}\text { Flexibilidad } \\
\text { laboral, salarios } \\
\text { de mercado. }\end{array}$ & $\begin{array}{l}\text { Flexibilidad } \\
\text { laboral, salarios } \\
\text { de mercado para } \\
\text { colegios } \\
\text { privados. } \\
\text { Estatuto docente } \\
\text { para municipales }\end{array}$ & $\begin{array}{l}\text { Flexibilidad } \\
\text { laboral, salarios de } \\
\text { mercado. }\end{array}$ \\
\hline \multirow[b]{2}{*}{ Información } & Rol Estado & $\begin{array}{l}\text { No es rol del } \\
\text { Estado entregar } \\
\text { Información. }\end{array}$ & $\begin{array}{l}\text { El Estado es } \\
\text { formalmente } \\
\text { responsable de } \\
\text { proveer } \\
\text { información. }\end{array}$ & $\begin{array}{l}\text { El Estado es } \\
\text { responsable de } \\
\text { proveer } \\
\text { información. }\end{array}$ \\
\hline & Medio de entrega & & $\begin{array}{l}\text { Vía web } \\
\text { (puntajes } \\
\text { pruebas } \\
\text { estandarizadas, } \\
\text { proyectos } \\
\text { educativos, } \\
\text { costos). }\end{array}$ & $\begin{array}{l}\text { Oficinas distritales } \\
\text { de choice apoyan, } \\
\text { guían decisiones } \\
\text { de padres. }\end{array}$ \\
\hline
\end{tabular}

$6 \quad$ Fuente: Elaboración Propia. 


\begin{tabular}{|l|l|l|l|l|}
\hline \multirow{2}{*}{$\begin{array}{l}\text { Modalidad de } \\
\text { entrega del } \\
\text { cupón }\end{array}$} & Destinatario & $\begin{array}{l}\text { Cupón entregado } \\
\text { directamente a las } \\
\text { familias. }\end{array}$ & $\begin{array}{l}\text { Cupón entregado } \\
\text { a colegios, por } \\
\text { MINEDUC. }\end{array}$ & $\begin{array}{l}\text { Cupón entregado a } \\
\text { colegios por } \\
\text { oficinas de choice. }\end{array}$ \\
\cline { 2 - 5 } & Criterio de entrega & Asistencia & Matrícula \\
\hline $\begin{array}{l}\text { Mecanismo de } \\
\text { elección y } \\
\text { postulación } \\
\text { escolar }\end{array}$ & Postulación & $\begin{array}{l}\text { Descentralizado: } \\
\text { Familia acude } \\
\text { directamente a } \\
\text { colegios para } \\
\text { postular. }\end{array}$ & $\begin{array}{l}\text { Descentralizado: } \\
\text { Familia acude } \\
\text { directamente a } \\
\text { colegios para } \\
\text { postular. }\end{array}$ & $\begin{array}{l}\text { Centralizado: } \\
\text { Postulaciones } \\
\text { canalizadas por } \\
\text { Oficina de Choice. }\end{array}$ \\
\hline
\end{tabular}

\subsection{FINANCIAMIENTO}

En cuanto al financiamiento la subvención entregada en Chile a los colegios municipales y particulares subvencionados cubre colegiatura (tal como proponen Friedman 1955, 2005; Chubb y Moe 1990) y alimentación (elemento ausente en los autores), pero no el transporte (como proponen Chubb y Moe 1990).

Como propuso Friedman $(1955,1995)$, la subvención en Chile admite copago determinado por la oferta, ya que los establecimientos deciden si cobran mensualidad a las familias de forma suplementaria a la subvención. Vale señalar, que los establecimientos particulares pagados cobran colegiatura para financiarse. En Chubb y Moe (1990), por el contrario, se propone un suplemento determinado por la demanda, donde los habitantes de un distrito pueden decidir colectivamente pagar más impuestos para aumentar la subvención escolar a todos los colegios del distrito.

Aunque Gallego y Sapelli (2007) caracterizaron el diseño chileno como subvención uniforme, en la actualidad no lo es, dado que (1) los montos son diferentes según tipo de jornada, nivel educativo y otros criterios, (2) hay subvenciones complementarias, como ruralidad y reforzamiento (Comunidad Escolar 2012) y (3) la Ley SEP admite montos distintos para estudiantes vulnerables (Elacqua y Santos 2013). Esto coincidirá con lo propuesto por Chubb y Moe (1990), para quienes el monto de la subvención debe corresponderse con las necesidades de los estudiantes.

\subsection{REGULACIÓN}

En Chile, los requisitos para adscribirse a la Ley de Subvenciones (MINEDUC 2012a) son similares a aquellos exigidos para establecer un colegio, a excepción del requisito (desde 2006) de que al menos $15 \%$ de sus estudiantes sea vulnerable socioeconómicamente, a menos que no haya suficientes postulaciones (MINEDUC 2010). Sin embargo, este requisito ha sido débilmente implementado y es mayoritariamente desconocido (Rojas 2009; Treviño, Salazar y Donoso 2011). En contraste, las teorías de CS (Chubb y Moe 1990, Friedman 1955, Friedman 2003; Friedman y Friedman 1982) proponen que los requisitos para formar un colegio sean mínimos y equivalentes a los que permiten recibir subvenciones. 
Los colegios que seleccionan también podrían recibir voucher según los teóricos (Friedman 1995; Chubb y Moe 1990). El modelo chileno en cambio es formalmente semirestringido, en tanto la selección está prohibida hasta sexto básico (MINEDUC 2012a), aun cuando pareciera estar ampliamente vigente (García-Huidobro, 2007). La actual reforma restringe la selección, pero el actual gobierno ha dado señales de volver a permitirla bajo ciertas condiciones.

Para integrar el sistema chileno, los colegios (reciban o no subvención) deben ceñirse al currículo nacional, el cual es más que "mínimo" ya que muchos profesores no alcanzan a ver todos los contenidos (Lemaitre, Cerri, Cox y Rovira, 2003). Esto se distancia de los autores, quienes señalan que solo debe haber estándares mínimos comunes.

Respecto al personal docente, mientras los autores proponen flexibilidad laboral y salarios determinados por el mercado (Friedman 1955; Friedman y Friedman 1982; Chubb y Moe 1990); en Chile esto aplica solo a los establecimientos privados. En los municipales, el Estatuto Docente regula la carrera, las contrataciones y las escalas de salarios (MINEDUC, 1997; Cox, 1997).

\subsection{INFORMACIÓN}

El rol estatal de informar ha tomado importancia paulatinamente en Chile. Recién en 1995 comenzaron a publicarse los resultados SIMCE, prueba creada siete años antes. Últimamente, el Estado ha asumido protagonismo, se establece en la Ley de Subvenciones la obligación de entregar información sobre establecimientos, calidad y cobertura (MINEDUC 2012a). Aunque el MINEDUC difunde resultados de pruebas estandarizadas, los proyectos educativos y los costos (principalmente mediante internet), las fuentes oficiales son poco utilizadas por las familias (Hernández y Raczynski, 2010).

Estas medidas alejan a Chile de Friedman, quien no consideraba necesaria la información estatal. Chile se acerca a Chubb y Moe, al reconocer el rol estatal de informar, pero está muy lejos aun del papel central que estos le otorgan. Para Chubb y Moe (1990) no basta con difundir, sino que se deben apoyar y guiar las decisiones de los padres mediante Oficinas Distritales de School Choice, que informan, coordinan visitas y reuniones con otros padres.

Estos planteamientos evidencian que la concepción de actor racional de Chubb y Moe (1990) es distinta a la de Friedman (1955), para el cual el cupón garantizaría la existencia de un poder de negociación por parte de la demanda. En Chubb y Moe (1990), en cambio, los agentes para decidir óptimamente requerirían mediación institucional. En Chile, la presunción de racionalidad es tan absoluta que no se incluye ningún mecanismo de empoderamiento de la demanda: ni oficinas, ni cupón.

\subsection{MODALDAD DE ENTREGA DE CUPÓN}

Ha habido escasa discusión sobre la entrega del voucher (cupón) en Chile, cuestión relevante al considerar que el diseño puede afectar las respuestas de padres y escuelas al incentivo (Levin, 1998). En Chile los recursos de la subvención se entregan directamente a los colegios (Elacqua y Santos, 2013) según la asistencia de sus estudiantes (opera como subsidio dependiente de la demanda). Esto se aleja de Friedman, para quien el cupón es un dispositivo material entregado directamente a las familias quienes con este en mano 
buscarían colegios (Friedman 2005; Friedman y Friedman, 1980, 1982). Esto supone cierto empoderamiento de las familias, porque se potencia su rol como clientes que al elegir exigen buen servicio.

La evidencia ha mostrado que lo material tiene efectos en los estados internos de las personas (Oviedo 2004; Searle 2010), por lo que recibir un papel con valor socialmente reconocido afectaría la toma de decisiones parentales. La eficacia del dispositivo no radica en su estructura física, sino en que el voucher representa "algo socialmente reconocido" (Searle, 2007), es decir, el pago de la colegiatura.

El uso como empoderador parental del voucher depende de su visibilidad, en tanto de esta surgen las capacidades institucionales del instrumento como convención social (Scharpf, 1997). Si este es invisibilizado, pierde potencia para fomentar la libertad y soberanía de su utilización. Las creencias respecto de las consecuencias de las acciones son relevantes (Hedström, 2005), por lo que una consecuencia no incide en la decisión si no es conocida por los actores. Un voucher invisibilizado, entonces, es menos potente.

Dada la ausencia de un voucher, Chile se asimila más a la propuesta de Chubb y Moe (1990), quienes no consideran la existencia de cupón. Para los autores, la subvención es entregada por la Oficina de Choice a los colegios, según matricula. Así, el caso chileno se distanciaría de la teoría Friedmaniana en la que supone inspirarse.

No habría, consecuentemente en Chile, subsidio "a la demanda", sino subsidio "dependiente de la demanda". Al no pasar por las manos de las familias, no se garantiza que se enteren de que tal subsidio existe, de qué monto tiene, ni que depende de su asistencia a la escuela. En definitiva, podría haber una invisibilización del "yo pago". Si bien, como un subsidio a la demanda, podría promover la competencia entre oferentes por captar estudiantes no necesariamente asegura el incentivo al comportamiento de cliente por parte de los padres. Este comportamiento, es el que llevaría a, tras una buena experiencia con el servicio, alentar a otros a adquirirlo, y tras una mala experiencia, a quejarse -exigiendo mejoras o compensaciones-, a abandonar su consumo -en este caso a cambiarse de colegio-, y a desalentar a otros a consumirlo (Noel, 2009). Sin comportamiento de cliente, no habría mecanismo que garantizara el cierre de escuelas de mala calidad que suponía el Voucher (Zamora, 2011).

La evidencia sugiere que los padres valoran las escuelas, independiente de su calidad (Corvalán y Román, 2012), tienden a no cambiar a sus hijos de colegios y que los colegios de baja calidad no siempre salen del sistema (De Iruarrizaga 2008; Román y Perticará, 2011). Esto sugiere que, en la práctica, el empoderamiento parental como cliente es escaso.

\subsection{MECANISMO DE ELECCIÓN Y POSTULACIÓN ESCOLAR}

La elección escolar en Chile es descentralizada: Cada familia acude directamente a los colegios a postular sin mediador, lo que coincide con la propuesta de Friedman (1955) ("eligen con los pies"). En cambio, para Chubb y Moe (1990) la elección y postulación es centralizada: la Oficina de Choice distrital entrega información a las familias y apoya su toma de decisiones. Luego, canaliza sus postulaciones y vincula familias y colegios en el distrito, asegurando que ningún postulante quede sin colegio. 


\section{LA REFORMA EDUCACIONAL (2014-2018) Y MODIFICACIONES AL "VOUCHER" CHILENO}

El segundo gobierno de Michelle Bachelet impulsó importantes reformas al sistema educacional que transformarán el "Voucher" vigente. En cuanto al financiamiento, con la Ley de inclusión (MINEDUC, 2015), los establecimientos públicos y privados que reciban subvención estatal no podrán cobrar a las familias, con lo cual se convierte en un sistema con subvención no suplementable. Para ello, el Estado aumentará progresivamente la subvención por estudiante a fin de no disminuir el gasto total por alumno?

En términos de Regulación, La ley de Carrera Docente regulará los salarios de los docentes de colegios municipales y particulares subvencionados, de acuerdo con su avance en el sistema de desarrollo profesional (MINEDUC, 2016). La Ley de inclusión (MINEDUC, 2015) también cambiará la regulación del CS: para optar a recibir la subvención del Estado, los colegios privados no podrán lucrar; esto generaría un $C S$ limitado, al imponer condiciones a los colegios para incorporarse al sistema. Además, la misma ley transformará al CS chileno en un sistema restringido al poner fin a la selección escolar en los establecimientos que reciben la subvención del Estado ${ }^{8}$.

Para poner fin a la selección, la ley está cambiando el mecanismo de elección y postulación escolar. Progresivamente ${ }^{9}$, se ha estado implementando un sistema estatal centralizado: los padres postulan a los establecimientos a través de una página web ${ }^{10}$, si los cupos son mayores que los postulantes en un colegio, todos los estudiantes serán admitidos, si los cupos son inferiores a los postulantes, se seleccionarán alumnos aleatoriamente, priorizando a los hijos de trabajadores del colegio al cual se postula, y a quienes tengan hermanos matriculados en el establecimiento ${ }^{11}$.

La implementación de la reforma implica cambios a nivel de Información: un sistema en línea de postulación entrega información sobre el proyecto educativo, actividades extracurriculares, infraestructura, etc. (MINEDUC, s.f.). Aunque mucha de esta información ya estaba disponible, al vincularlo con el sistema de postulación, las familias acceden en mayor medida a la información. Esto no alcanza a ser equivalente al rol de apoyo a las decisiones que constituían las Choice Office de Chub y Moe, pero sí otorga mayor importancia al rol de información del Estado.

Aunque el $C S$ chileno cambia en términos de financiamiento, regulación, información y el mecanismo de elección y postulación escolar, no se modifica la modalidad de entrega del cupón: el $C S$ chileno tras la plena vigencia de la reforma, seguirá siendo un sistema de subsidio dependiente de la demanda.

\footnotetext{
Los colegios privados que no reciben subvención podrán seguir cobrando mensualidad. Algunos establecimientos particulares subvencionados podrán dejar de recibir subvención si optan por continuar cobrando mensualidad.

8 Los colegios privados que opten por no recibir subvención podrán continuar seleccionando estudiantes.

9 El sistema ya está funcionando en las regiones de Tarapacá, Coquimbo, O’Higgins, Los Lagos y Magallanes.

10 https://www.sistemadeadmisionescolar.cl/

${ }_{11}$ Con el nuevo proceso de admisión, el 93\% de las familias obtuvo un cupo en uno de sus colegios preferidos y el $70 \%$ en su primera opción, por lo que la libre elección escolar sigue siendo un componente central en el sistema. Fuente: Emol.com http://www.emol.com/noticias/Nacional/2017/12/20/888089/Fin-a-la-seleccion-El-93-de-las-familias-obtuvo-un-cupo-enuno-de-sus-colegios-preferidos.html
} 
En términos generales, los cambios que generan estas reformas alejan al CS chileno de las teorías de Friedman, y Chubb y Moe, en aspectos relativos a la liberalización de la oferta, al incrementar los requisitos para recibir subvención, regular la carrera docente y prohibir la selección escolar. Sin embargo, las reformas no limitarían la libertad de la demanda; por el contrario, podrían ampliar la misma, al evitar que el precio de los colegios o la selección que estos realizan restrinja las elecciones de las familias.

No obstante, la evolución del CS chileno debe leerse en el contexto de cambio de gobierno. La actual administración de Sebastián Piñera -aunque no ha propuesto modificaciones- ha dado señales en el sentido de reducir las regulaciones en selección y copago.

\section{CONCLUSIONES}

Claramente el CS chileno no es el Voucher de Friedman: la no entrega del cupón a las familias es un elemento de diseño crucial que podría incidir en las decisiones de la demanda educativa. Se propone utilizar el concepto de "CS con subsidio dependiente de la demanda" para Chile, porque la subvención la recibe el oferente según la asistencia de su demanda educativa.

Evidenciar tal distinción es relevante, en tanto continuamente se han desarrollado políticas de profundización del CS chileno sin claridad del mismo. En el sistema chileno, en concordancia con Friedman, y Chubb y Moe, hay subvención a la colegiatura, no hay limitación geográfica a la elección, se evita la selección hasta sexto básico, y hay flexibilidad laboral y salarios determinados por el mercado para colegios privados. La elección descentralizada de Friedman aparece en Chile, estando ausente en Chubb y Moe. A su vez, los elementos tomados de Chubb y Moe, ausentes en Friedman, son, además del subsidio dependiente de la demanda, la subvención heterogénea y el rol del Estado en la información. Esto hace que, en definitiva, se requiera menos Friedman, y más Chubb y Moe para entender el sistema chileno.

A pesar de la amplia similitud del modelo chileno vigente con el de Chubb y Moe, en Chile no existen las Choice Office que los autores proponían, ni tampoco otro mecanismo de empoderamiento de la demanda que lo reemplace -como podría ser el cupón de Friedman.

Las distancias de diseño entre tales teorías y el modelo chileno pueden deberse en parte a orígenes distintos. Las teorías de $C S$ surgieron ante la baja calidad y alta segregación escolar. El modelo chileno no surge por discusión ni consenso, sino por una postura política de la Junta de Gobierno que pretendía hacer un giro en el modelo de desarrollo, instalando el Estado subsidiario. Así, la instalación no pasó por el ciclo de discusión, aprobación e implementación de las políticas públicas (Stein, Tommasi, Echebarría, Lora y Payne, 2006), sino que fue impuesto en un contexto autoritario.

Además, la Ley de Carrera Docente y la Ley de Inclusión modificarán el "Voucher" chileno: al regular la carrera docente, poner fin al lucro, al copago y a la selección, el modelo chileno descarta algunos elementos liberalizadores de la oferta planteados por los teóricos de los $C S$, sin limitar la libertad de la demanda. Al establecer un sistema centralizado de elección escolar, se acerca relativamente a las propuestas de Chub y Moe, promoviendo un rol estatal más protagónico en otorgar información. 
Más allá de la reforma en implementación, el desarrollo del CS Chileno -hacia el futuro- puede seguir experimentando modificaciones, especialmente en el contexto actual de cambio de gobierno.

\section{REFERENCIAS BIBLIOGRÁFICAS}

Acevedo, I., y Valenzuela, J. (2011). Ley de Subvención Escolar Preferencial: ¿Más oportunidades de elección para los estudiantes vulnerables? Santiago: Centro de Investigación Avanzada en Educación (CIAE) y Departamento de Economía Universidad de Chile. Consulta el 3 de enero de 2013.

Bellei, C. (2008). The public-private school controversy in Chile. En Ch. Rajashri and P. E. Peterson (Eds.), School Choice International: Exploring Public-Private Partnerships (pp. 165-192 ), Cambridge, Massachusetts: MIT Press.

Chubb, J. and Moe, T. (1990). Politics markets and America's schools. Washington, D.C.: The Brookings Institution.

Comunidad Escolar. (2012). Valores de otras subvenciones. Santiago: Coordinación Nacional de subvenciones. Consulta el 21 de septiembre de 2012 (http://www.comunidadescolar.cl/ documentacion/Subvencion/informes/valor-subvenciones-MARZO-2012.pdf).

Coons, J. and Sugarman, S. (1977). Education by choice: The case of family control. Brekeley, Los Angeles, London: University of California Press.

Cornejo, R. (2006). El experimento educativo chileno 20 años después: Una mirada crítica a los logros y falencias del sistema escolar. Revista Iberoamericana sobre Calidad, Eficacia y cambio en Educación (REICE) 1, 118-129.

Corvalán, J. y Román, M. (2012). La permanencia de escuelas de bajo rendimiento crónico en el cuasi mercado educativo chileno. Revista Uruguaya de Ciencia Política 1, 43-64.

Cox, C. (1997). La reforma de la educación chilena: contexto, contenidos, implementación. Colección de estudios CIEPLAN 45, 5 - 32.

Cruz, P. (2006). La educación formal en Chile desde 1973 a 1990: un instrumento para el proyecto de Nación. En Viejas y Nuevas alianzas entre América latina y España: XII Encuentro de Latino Americanistas Españoles. Salamanca, España.

Donoso, S. (2006). Financiamiento y gestión de la educación pública chilena de los años 90. Cuadernos de Pesquisa, 36(127), 151-172.

Donoso, S. \& Schmal, R. (2002). Financial models for public education in Chile and the requirements for their adjustment. Revista Electrónica de Investigación Educativa, 4(2), 46-84.

EdChoice (2018). Types of School Choice. Recuperado de: https://www.edchoice.org/school-choice/ types-of-school-choice/

Elacqua G., y Santos, H. (2013). Preferencias reveladas de los proveedores de educación privada en Chile El caso de la Ley de Subvención Escolar Preferencial. Gestión y política pública 22(1), 85-129.

Elacqua, G., Montt, P. y Santos, H. (2012). Financiamiento Compartido en Chile: Antecedentes, Evidencia y Recomendaciones. Santiago: Instituto de políticas públicas, Diego Portales.

Espinoza O. y González, L. (1993). La experiencia del proceso de desconcentración y descentralización educacional en Chile 1974-1989. Documento Programa interdisciplinario de investigación en educación (PIIE). Consulta el 3 de enero de 2013 (http://www.bligoo.com/media/users/1/91093/ files/descentralizacion_oscar_espinoza2.pdf).

Friedman, M. (1955). The Role of Government in Education. In R. Solo (Ed.). Economics and the public interest (pp. 123-144). New Brunswick, NJ: Rutgers University Press.

Friedman, M. (1995). Public schools: Make them private. Cato institute briefing paper, 23. Consulta el 30 de noviembre de 2012 (http://www.cato.org/sites/cato.org/files/pubs/pdf/bp023.pdf) 
Friedman, M. (2003). Milton Friedman on Vouchers. CNBC Interview. Consulta el 13 de abril de 2018. Recuperado de :https://www.edchoice.org/who-we-are/our-founders/the-friedmans-onschool-choice/article/milton-friedman-on-vouchers/.

Friedman, M. (2005). Free to choose. The wall street journal, 9. Consulta el 13 de abril de 2018. Recuperado de: https://www.utdallas.edu/ plewin/FriedmanOnVouchersFreeToChoose.pdf.

Friedman, M. \& Friedman, R. (1980). Free to choose. New York y London: HBJ.

Friedman, M. \& Friedman, R. (1982). Capitalism and freedom. Chicago: The University of Chicago Press.

Gallego, F. y Sapelli, C. (2007). El financiamiento de la educación en Chile: una evaluación. Revista Pensamiento Educativo 1, 263 - 284.

García-Huidobro, S. (2007). La "selección de alumnos" en la Ley General de Educación. Docencia, 32, 20-27.

Hedström, P. (2005). Dissecting the social: On the principles of analytical sociology. Cambridge: Cambridge University Press.

Hernández, M. y Raczynski, D. (2010). Cómo eligen las escuelas las familias chilenas de estratos medios y bajos. Información, representaciones sociales y segregación. Ponencia en Primer Congreso interdisciplinario de investigación en educación, Pontificia Universidad Católica de Chile.

Iruarrizaga de, F. (2008). Creación y destrucción de firmas en el mercado de la educación. Determinantes de cierre de establecimientos. Tesis para optar al título de Ingeniero Comercial, Instituto de Economía, Pontificia Universidad Católica de Chile, Santiago.

Junta Militar. (1974). Declaración de principios del gobierno de Chile. Archivo Chile. Consulta el 17 de agosto de 2012 (http://www.archivochile.com/Dictadura_militar/doc_jm_gob_pino8/DM docjm0005.pdf).

Larrañaga, O. (1994). Reformas de la educación: una tarea urgente, en Chile hacia el 2000. Santiago: Ideas para el desarrollo, Centro de Estudios Públicos.

Lemaitre, M., Cerri, M, Cox, C y Rovira, C. (1993). La reforma de la educación media. En C. Cox (Ed.) Políticas educacionales en el cambio de siglo. La reforma del sistema escolar de Chile (pp. 317-374). Santiago: Editorial Universitaria.

Levin, H. (1968). The failure of the public schools and the free market remedy. The Urban Review, 2(7), 32-37.

Levin, H. (1992). Market approaches to education: Voucher and School Choice. Economics of education review, 11(4), 279-285.

Levin, B. (1998). Educational vouchers: effectiveness, choice, and costs. Journal of Policy Analysis and Management, 1 17(3), 373-391.

Mankiw, G. (2004). Principios de Economía. Harvard University: McGraw-Hill

McEwan, P. (2001). The Effectiveness of Public, Catholic, and Non Religious Private Schools in Chile's Voucher System, Education Economics, 9(2), 103-128

MINEDUC (1997). Decreto con fuerza de ley n ${ }^{\circ}$. Comunidad Escolar. Consulta el 3 de enero de 2013 (http://subvenciones.mineduc.cl/seccion/documento/2D2002040416132811094.pdf).

MINEDUC (2009). Ley 20.370: Establece Ley General de Educación. Biblioteca del Congreso Nacional de Chile. Consulta el 28 de diciembre de 2012 (http://www.ley chile.cl/ Navegar?idNorma $=1006043)$.

MINEDUC (2010). Guía 600 MINEDUC - Subvenciones. Contacolegios. Consulta el 21 de septiembre de 2012 (http://www.google.cl/url?sa=tyrct=jyq=yesrc=sysource=webycd=1 ycad= rjay ved=0CCQQFjAAyurl=http $\% 3 \mathrm{~A} \% 2 \mathrm{~F} \% 2 \mathrm{Fwww}$. contacolegios.cl $\% 2 \mathrm{Fsaveasdialog}$.asp $\% 3 \mathrm{~F}$ c\%3D21502\%26p\%3D2\%26i\%3D12373yei=c7pcUNP2IIbm9ASGvoCgDwyusg=AFQjCNE9 vq2Md_EJxQExQPfnQa94ACoTZg)

MINEDUC (2012a). Decreto con fuerza de ley $\mathrm{n}^{\circ}$ 2: Subvención del Estado a establecimientos educacionales. Biblioteca del Congreso Nacional de Chile. Consulta el 24 de septiembre de 
2012 (http://www.leychile.cl/Navegar?idNorma=127911yidVersion=2012-03-01).

MINEDUC (2012b). Ley 20.248: Establece Ley de Subvención Escolar Preferencial. Biblioteca del Congreso Nacional de Chile. Consulta el 4 de enero de 2013 (http://www.leychile.cl/ Navegar? idNorma=269001 ybuscar=ley+20248).

MINEDUC (2015). Ley 20845: Establece Ley de Inclusión escolar que regula la admisión de los y las estudiantes, elimina el financiamiento compartido y prohíbe el lucro en establecimientos educacionales que reciben aportes del Estado. Biblioteca del Congreso Nacional de Chile. Consulta el 3 de enero de 2018 (https://www.leychile.cl/Navegar?idNorma=1078172).

MINEDUC (2016). Ley 20903: Crea el sistema de desarrollo profesional docente y modifica otras normas". Biblioteca del Congreso Nacional de Chile. Consulta el 3 de enero de 2018 (https:// www.leychile.cl/Navegar?idNorma=1087343).

MINEDUC (s.f.) Nuevo sistema de admisión. Ayuda MINEDUC: atención ciudadana. Consulta el 13 de abril de 2018. Recuperado en: https://www.ayudamineduc.cl/ficha/nuevo-sistema-deadmision-0

Mizala, A. y Romaguera, P. (1998). Desempeño escolar y elección de colegios: la experiencia chilena. Centro de Economía Aplicada Universidad de Chile, Serie Economía, 36, 1-43.

Noel, H. (2009). Consumer Behaviour. Switzerland: Ava

OPECH. (2009). De actores secundarios a estudiantes protagonistas. Santiago: OPECH.

Oviedo, G. (2004). La definición del concepto de percepción en Psicología con base en la teoría Gestalt. Revista de estudios sociales 18, 89-96.

Parkin, M. (2006). Microeconomía. México: Pearson Educación.

Rojas, M. (2009). ¿Es posible imaginar escuelas más integradas? Docencia, 39, 31 - 39.

Román, M. y Perticará, M. (2011). La elección y permanencia en colegios de baja calidad en Chile. Documento del Centro de Investigación de Educación (CIDE), Universidad Alberto Hurtado.

Sapelli, C. y Torche, A. (2002) Subsidios al alumno o a la escuela: efectos sobre la elección de colegios públicos. Cuadernos de Economía, 39(117), 175-202.

Searle, J. (2007). Social Ontology: some Basic Principles. Papers: Revista de sociología, 80, 51-71.

Searle, J. (2010). Los principios básicos de la ontología social. En J. Noguera (Ed.) Teoría Sociológica Analítica (pp. 63-84). Madrid: Centro de Investigaciones Sociológicas.

Scharpf, F. (1997). Games real actors play: Actor-centered institutionalism in policy research. Boulder, CO: Westview Press.

Stein, E., Tommasi, M., Echebarría, K., Lora, E. y Payne, M. (2006). La política de las políticas públicas. Progreso económico y social en América Latina Informe 2006. Banco Interamericano de Desarrollo (BID), David Rockefeller Center for Latin American Studies y Harvard University.

Treviño, E., Salazar, F. y Donoso, F. (2011). ¿Segregar o incluir? Esa no debería ser una pregunta en educación. Docencia, 45, 34-47.

Valenzuela, J., Labarrera, P. y Rodríguez, P. (2008). Educación en Chile: Entre la continuidad y las rupturas. Principales hitos de las políticas educativas. Revista iberoamericana de educación, 48, 129-145.

Zamora, G. (2011). Movilidad escolar en Chile. Análisis de las implicancias para la calidad y equidad de la educación. Estudios Pedagógicos, 37(1), 53-69. 